\title{
Comparative Evaluation of Bond Strength of Fifth, Sixth, Seventh, and Eighth Generations of Dentin Bonding Agents: An In Vitro Study
}

\author{
Unnavi Chauhan ${ }^{1}$, Ruchika Dewan ${ }^{2}$, Nikhil G Goyal ${ }^{3}$
}

\begin{abstract}
Aim and objective: To evaluate and compare the shear bond strength of the fifth, sixth, seventh, and eighth generations of bonding agents. Methods and materials: Forty freshly extracted premolars were selected and assigned into five groups: group I-fifth-generation bonding agent (SwissTEC SL Bond), group II—sixth-generation bonding agent (One Coat), group III—seventh-generation bonding agent (One Coat 7.0), group IV-eighth-generation bonding agent (One Coat 7 Universal), and group V-control group. With the help of an air rotor, the coronal dentin was exposed. The dentin bonding agents were applied, which was then followed by the placement of composite on surface which was earlier exposed. Shear bond strength testing was then done using universal testing machine.
\end{abstract}

Statistical analysis: Data were analyzed using SPSS version 21. The intergroup comparison was done using one way analysis of variance along with post hoc Tukey's test.

Results: Maximum shear bond strength was found in the eighth generation of bonding agent followed by the fifth, seventh, and lastly, the sixth generation $(p<0.05)$.

Conclusion: The greatest shear bond strength to dentin was seen in the eighth generation of dentin bonding agent with a great advantage of fewer steps involved in the procedure as compared to other generations of dentin bonding agents.

Keywords: Bond Strength, Dentin Bonding Agents, Eighth-Generation Bonding Agent.

Journal of Operative Dentistry and Endodontics (2020): 10.5005/jp-journals-10047-0103

\section{INTRODUCTION}

The practice of adhesive dentistry is rapidly evolving. Since many years now, dentistry has strived to achieve good adhesion of resin composite to tooth substrate, as less microleakage and better restoration stability is expected with a reliable bonding system. ${ }^{1,2}$ Composite resins are being used with a greater frequency today as an aesthetic alternative to dental amalgam. This has led to various developments in the field of adhesive restorative dentistry. ${ }^{3,4}$

Dental adhesive systems have been evolving through many generations with which we have witnessed many changes in the chemistry, mechanism of operation, the number of steps involved in the procedure, the technique of application, and their clinical effectiveness. When compared with etch and rinse adhesives, several advantages have been seen in self-etching adhesives. ${ }^{5,6}$ Dentin bonding refers to micromechanical coupling of restorative materials, particularly composites, to human dentin via an intermediary adhesive resin layer. ${ }^{7}$

The placement of composite restorations is followed by the pretreatment of the cavities with an adhesive system. The degree of interface adhesion and chemical stability is critical for the successful clinical use of any resin. The word adhesion has been derived from the Latin word "adherence," which means to stick. Adhesion refers to the forces or energies between atoms or molecules at an interface that holds two phases together. Bonding agents are used to promote adhesion between composite resin and dental structure. ${ }^{5}$ The bonding highly depends on the formation of resinimpregnated layer, i.e., hybrid layer where an important step is the removal of smear layer which is attached to the dentine.
${ }^{1}$ ITS Dental College, Greater Noida, Uttar Pradesh, India

2,3 Department of Conservative Dentistry and Endodontics, ITS Dental College, Greater Noida, Uttar Pradesh, India

Corresponding Author: Unnavi Chauhan, ITS Dental College, Greater Noida, Uttar Pradesh, India, Phone: +9109891142001, e-mail: unnavichauhan96@gmail.com

How to cite this article: Chauhan U, Dewan R, Goyal NG. Comparative Evaluation of Bond Strength of Fifth, Sixth, Seventh, and Eighth Generations of Dentin Bonding Agents: An In Vitro Study. J Oper Dent Endod 2020;5(2):69-73.

Source of support: Nil

Conflict of interest: None

In current times, the development of newer products is increasing at an unbeatable rate. Dentin adhesives are available in many systems like three-step, two-step, or single-step systems, which entirely depends on how the steps of etching, priming, and bonding to the tooth surface are accomplished. . $^{8-11}$

Dentists thought that the fourth generation of dentin bonding system was quite complex and time-consuming to use, and demanded simpler solutions. The first simplification was the fifth generation of bonding agents, systems in which the primer and adhesives were mixed together and supplied as a single system. Dentists wanted even simpler systems which is why two more systems were evolved, consisting of an acidic primer and a bonding resin referred to as a sixth-generation adhesive, and

(0) The Author(s). 2020 Open Access This article is distributed under the terms of the Creative Commons Attribution 4.0 International License (https:// creativecommons.org/licenses/by-nc/4.0/), which permits unrestricted use, distribution, and non-commercial reproduction in any medium, provided you give appropriate credit to the original author(s) and the source, provide a link to the Creative Commons license, and indicate if changes were made. The Creative Commons Public Domain Dedication waiver (http://creativecommons.org/publicdomain/zero/1.0/) applies to the data made available in this article, unless otherwise stated. 
another in which the etchant, primer, adhesive are combined into one single delivery system marked as seventh generation of adhesive systems.

Total etch adhesive can be two-step adhesives or three-step adhesives. Although three-step etch-and-rinse adhesives have been considered the clinical gold standard in dental bonding, this issue seems to be controversial, according to recent systematic reviews of the literature. The retention rates of three-step etchand-rinse systems are quite variable, with an annual failure rate varying from 0 to $16 \%{ }^{3}$ Furthermore, Peumans and others in their systematic review reported that at least three out of 10 three-step etch-and-rinse adhesives did not meet the requirements of the American Dental Association guidelines for provisional and full acceptance of the restorations, and in some of the clinical studies reviewed, they did not gain full acceptance. It is claimed that the use of a hydrophobic resin coating in the three-step etch-and-rinse is responsible for better in vitro and in vivo performance than that of their two-step counterparts. ${ }^{12}$

Presently the concept of "self-etch" adhesives was introduced in which the sixth-generation bonding agents consist of acidic primer and bonding resin separately, while the seventh-generation bonding agents are self-etch adhesives with combination of etchant, primer, and bonding agent in one component and applied as a single step.

The basic composition of self-etch primers and self-etch adhesive systems an aqueous solution of water is to provide the medium for ionization and action of these acidic resin monomers.

Self-etch adhesive systems contain HEMA monomer to increase the wettability of dentin surface while bifunctional or multifunctional monomers are added to provide strength. Because self-etch adhesive systems do not require a separate acid conditioning step and moist postrinse control, they are considered simplified adhesive materials. They offer some advantages over conventional etch-and-rinse systems, such as reduction of postoperative sensibility and less sensitive technique. Another advantage is that infiltration of adhesive resin tends to occur simultaneously with the self-etch process. ${ }^{13}$

In light of these developments, the study was undertaken to investigate and compare the bond strength of four different generations of bonding agents.

\section{Materials and Methods}

Forty freshly extracted noncarious human teeth were selected for the study. The teeth were embedded vertically in cold-cure acrylic resin with the help of a custom-made modeling wax mold of dimension $1 \mathrm{~cm} \times 1 \mathrm{~cm} \times 1 \mathrm{~cm}$. The occlusal surfaces of the teeth were reduced with the help of a 245 carbide bur under constant spray of water to expose a flat dentin surface.

The prepared samples were divided into four experimental groups and one control group for the application of different bonding agents as follows:

- Group I: $(n=8)$ Fifth-generation bonding agent (SwissTEC SL Bond).

- Group II: ( $n=8)$ Sixth-generation bonding agent (One Coat).

- Group III: $(n=8)$ Seventh-generation bonding agent (One Coat 7.0).

- Group IV: $(n=8)$ Eighth-generation bonding agent (One Coat 7 Universal).

- Group V: $(n=8)$ Control group (no bonding agent was used)
In each group, the bonding agent was applied using the manufacturer's instructions onto the surface and light cured. The composite was placed in a two-layer increment using a plastic mold of dimension $2 \mathrm{~mm}$ diameter $\times 3 \mathrm{~mm}$ height. The composite was light cured for 20 seconds. All the samples were subjected to shear bond strength analysis (Fig. 1).

The shear bond strength testing was done using a universal testing machine, UTM, (INSTRON). The specimen was attached to the device and subjected to a shear force in the UTM at a cross-head speed of $1.5 \mathrm{~mm} /$ minute in a compression mode. The bonded composite cylinder was positioned horizontally so that the shearing blade is perpendicular at composite-dentin interface. Each specimen was loaded until failure. Shear force required to de-bond the specimen was recorded. The bond strength was calculated in kgf which was converted into N.

Data obtained were then tabulated and statistically analyzed using Statistical Package for Social Sciences (SPSS) version 21.

The intergroup comparison of the variable was done using one way analysis of variance along with post hoc Tukey's test.

Null hypothesis: There is no difference in the bond strength between the different-generation bonding agents.

\section{RESULTS}

The null hypothesis for this study was rejected as the difference between the experimental groups was found to be statistically significant.

Table 1 shows the descriptive of force with respect to five groups. The result being as follows:

Group IV (eighth generation) > Group I (fifth

generation) > Group III (seventh generation) > Group II (sixth Generation) > Group V (Control)

Table 2 shows the intergroup comparison and the difference in force (Newtons) is found to be statistically significant $(p<0.05)$.

The eighth-generation adhesives showed a significantly higher shear bond strength to dentin when compared to fifth, seventh, and sixth generations, respectively.

Figure 2 shows the intergroup comparison of the bond strength of the different-generation dentin bonding agents.

\section{Discussion}

The primary objective when assessing the bond strength of a bonding agent is to assess its retention to the dental hard structures. Advancements have aimed to enhance the bonding quality and shorten the time consumption in application. The factors affecting bond strength are the type of tooth, dentin surface, type of bond strength to be tested (shear or tensile), type of bonding agent used, storage media, composite restorative material, and testing procedure.

In the present in vitro study, the four tested bonding agents were fifth-generation SwissTEC SL Bond (Total-etch), sixthgeneration One Coat, seventh-generation One Coat 7.0 (Self-etch), and eighth-generation One Coat 7 (Universal).

In this study, highest mean shear bond strength was observed in eighth-generation dentin adhesives One Coat 7 (Universal)

compared to sixth-, seventh-, and fifth-generation adhesives.

According to the results of our study, the eighth-generation adhesive was found to be better than the fifth-generation bonding agent $(p<0.05)$. Eighth generation bonding agents are said to have 


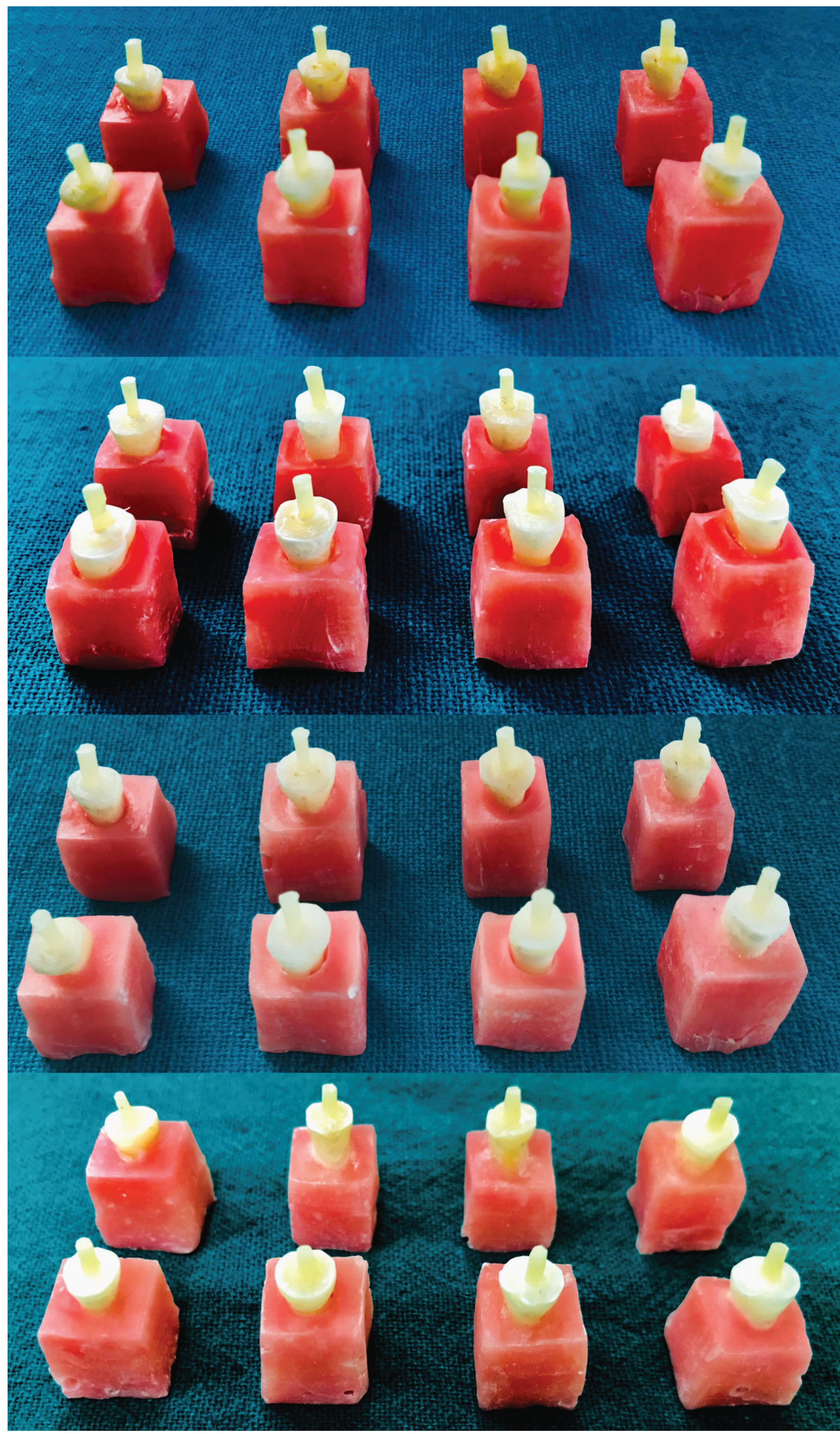

Fig. 1: Composite restorations on the exposed coronal dentin of the occlusal surface 
Table 1: Mean and standard deviation for all the groups in Newtons

\begin{tabular}{|c|c|c|c|c|c|c|c|}
\hline \multicolumn{8}{|c|}{ Descriptives of force (Newtons) } \\
\hline \multirow[t]{2}{*}{ Group } & \multirow[t]{2}{*}{$N$} & \multirow[t]{2}{*}{ Mean } & \multirow[t]{2}{*}{ Std. deviation } & \multicolumn{2}{|c|}{ 95\% confidence interval for mean } & \multirow[t]{2}{*}{ Minimum } & \multirow[t]{2}{*}{ Maximum } \\
\hline & & & & Lower bound & Upper bound & & \\
\hline I & 8 & 26.3500 & 8.09516 & 19.5823 & 33.1177 & 12.74 & 39.22 \\
\hline II & 8 & 17.7688 & 9.00804 & 10.2378 & 25.2997 & 1.96 & 29.41 \\
\hline III & 8 & 22.4263 & 6.92111 & 16.6401 & 28.2124 & 9.80 & 29.41 \\
\hline IV & 8 & 40.4463 & 14.27748 & 28.5100 & 52.3825 & 21.57 & 60.80 \\
\hline V & 8 & 4.9000 & 2.34265 & 2.9415 & 6.8585 & 1.96 & 8.82 \\
\hline
\end{tabular}

Table 2: Intergroup comparison with post hoc Tukey's and ANOVA

\begin{tabular}{|c|c|c|c|c|c|}
\hline \multicolumn{6}{|c|}{ Post hoc pairwise comparison } \\
\hline & GrI & Gr II & Gr III & GrIV & GrV \\
\hline Gr I & - & $0.331, \mathrm{NS}$ & 0.905, NS & $0.027, \mathrm{~S}$ & $<0.0001, \mathrm{~S}$ \\
\hline Gr II & $0.331, \mathrm{NS}$ & - & $0.837, \mathrm{NS}$ & $<0.0001, \mathrm{~S}$ & $0.051, \mathrm{NS}$ \\
\hline Gr III & $0.905, \mathrm{NS}$ & $0.837, \mathrm{NS}$ & - & $0.003, \mathrm{~S}$ & $0.004, \mathrm{~S}$ \\
\hline Gr IV & $0.027, \mathrm{~S}$ & $<0.0001, \mathrm{~S}$ & $0.003, \mathrm{~S}$ & - & $<0.0001, \mathrm{~S}$ \\
\hline Gr V & $<0.0001, \mathrm{~S}$ & $0.051, \mathrm{NS}$ & $0.004, \mathrm{~S}$ & $<0.0001, \mathrm{~S}$ & - \\
\hline
\end{tabular}

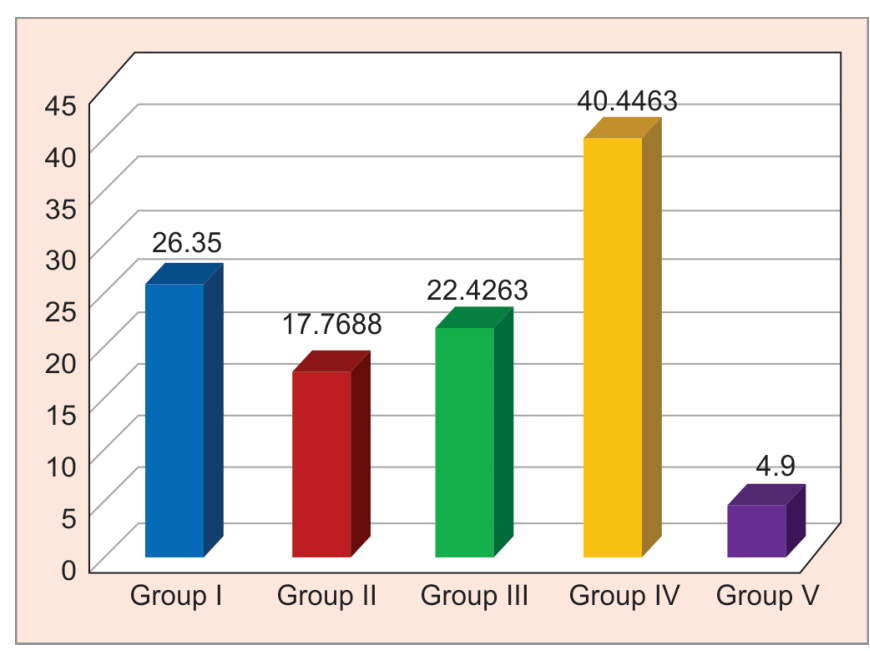

Fig. 2: Graphical representation of the mean bond strength of the five groups

a higher bond strength than the seventh generation as it contains more number of microsized cross-linking functional monomers in spite of both of them having functional monomers, cross-linking monomers, solvent, inhibitors, and activators. Exceptional bonding values on enamel and dentin are seen in One Coat 7 Universal bonding agent.

One Coat 7 Universal bonding agent can be used with the self-etch, selective-etch, and total-etch technique. Nanofiller technology is incorporated into the bonding agent to produce a perfectly homogenous bond layer and to provide improved mechanical properties. Our study gave results similar to a study done by Joseph et al. ${ }^{14}$ and Kamble et al. ${ }^{15,16}$ who concluded that eighth generation of bonding agent looked to be much better with respect to many factors than the sixth and seventhgeneration bonding agents. Leite et al. ${ }^{17}$ also concluded that the use of self-etching primers is recommended instead of the total etching technique to attain higher bond strength. The present results have been proved to be consistent with the study conducted by Mithiborwala ${ }^{18,19}$ who said that there is increased thickness of hybrid layer by $25-30 \%$. The density and length of the resin tags were found to be quite adequate in eighth-generation adhesives due to the milder acid-etching in these systems.

In case of the fifth-generation adhesives (SwissTEC SL Bond) which is based on the total-etch technique, enamel conditioning with phosphoric acid results in the formation of microporosities where resin penetrates to form "prism-like" resin tags. This yields an enamel bonding predominantly micromechanical. When we prepare a cavity, the uppermost layer of tooth tissue gets covered with 1.0- $\mu \mathrm{m}$ layer of cutting debris called smear layer. The orifices of the dentin tubules get obstructed by debris tags which may extend into the tubules. They are known as smear plugs. These smear plugs are contiguous with smear layer consisting of shattered and crushed hydroxyapatite, as well as fragmented and denatured collagen. Collagen can get exposed by highly aggressive acids, which will further affect the bond strength as it may not allow the adhesive resins to penetrate completely leaving behind an un-infiltrated weak collagenous layer of dentin susceptible to long-term degradation.

One Coat 7.0 (seventh-generation bonding agent) performed better than the sixth-generation bonding agent. Fewer components save time and minimize confusion and no reapplication or waiting period is required. One Coat 7.0's special formulation demineralizes the dentin and enamel surfaces, thus solubilizing the smear layer without ever removing it from the open tubules. The end result is a low gap formation, which prevents microleakage. This study showed that One Coat 7.0 showed very low bond strength in comparison with the other bonding agents.

The results of this study were consistent with a study done by Somani et al. ${ }^{20}$ who did a study on the sixth-and seventh-generation bonding agents and found out that the microleakage value was higher in the seventh generation than the sixth generation.

The sixth-generation bonding systems tried to eliminate the etching step, or to include it chemically in one of the other steps: 
self-etching primer + adhesive or self-etching adhesive with two bottles or unit dose containing acidic primer and adhesive. The mixture of hydrophilic and hydrophobic resin components is then applied to the tooth substrate. The evaluations showed a sufficient bond to conditioned dentin while the bond with enamel showed lower bond strength. A possible factor for this could be that the sixth-generation systems are composed of an acidic solution that cannot be kept in place have a $\mathrm{pH}$ that is not enough to properly etch enamel.

However, there was no statistically significant difference between the sixth-generation and seventh-generation bonding agent ( $p=0.837$ ) and fifth- and seventh-generation bonding agent $(p=0.905)$. Afshar et al. ${ }^{21}$ stated the same results failing to find any statistically significant difference between the fifth- and seventhgeneration or the sixth- and seventh-generation bonding agents. There is a significant difference found between the fifth-generation and eighth-generation bonding agent $(p<0.0001)$.

Considering the composition and the substrate treatment by adhesive factor. The fact that the chemical composition of adhesive systems determines their clinical success has been reported by many studies. Microsized cross-linking agents and MDP monomers in eighth-generation adhesive promote chelation with calcium and the formation of hydrogen bridges with dentin components which may be the significant factor resulting in higher shear bond strength values in the eighth generation.

\section{Conclusion}

Within the limitations of the present in vitro study, it can be concluded that the eighth-generation bonding agent showed higher mean bond strength to dentin than the fifth, followed by the seventh, and lastly the sixth-generation bonding agent. The highest value was showed by One Coat 7 which also requires fewer steps and is thus less time consuming.

\section{One Coat 7 Universal $>$ Swiss tec SL Bond $>$ One Coat} $7>$ One Coat $>$ Control group

\section{References}

1. Hegde MN, Bhandary S. An evaluation and comparison of shear bond strength of composite resin to dentin, using newer dentin bonding agents. J Conserv Dent 2008;11(2):71-75. DOI: 10.4103/09720707.44054.

2. Naughton W, Latta M. Bond strength of composite to dentin using self-etching adhesive systems. Quintessence Int 2005;36(4):259-262. PMID: 15835421.

3. Nair M, Paul J, Kumar S, et al. Comparative evaluation of the bonding efficacy of sixth and seventh generation bonding agents: an in-vitro study. J Conserv Dent 2014;17(1):27-30. DOI: 10.4103/09720707.124119.

4. Lopes GC, Marson FC, Vieira LC, et al. Composite bond strength to enamel with self-etching primers. Oper Dent 2000;29:424-429. PMID: 15279482.
5. Ravikumar N, Shankar P, Indira R. Shear Bond Strength of two dentin Bonding Agents with two desensitizers. J Conserv Dent 2011;14(3):247-251. DOI: 10.4103/0972-0707.85802.

6. Lopes GC. Shear bond strength of acetone based one bottle adhesive system. Braz Dent J 2006;17(1):39-43. DOI: 10.1590/s010364402006000100009.

7. Sheenam M, Shinam $P$, Rajan D, et al. A comparative evaluation of Bond Strength and interfacial microleakage of different Bonding Agents. BFUDJ 2014;5. DOI: 10.5005/jp journals-10005-1396.

8. Sachdeva B, Dua P, Mangla R, et al. Bonding efficacy of 5th, 6th, 7th \& 8th bonding agents on primary teeth. IOSR J Dent Med Sci (IOSRJDMS) 2018;17(3):61-66. DOI: 10.9790/0853-1703136166.

9. Dey S, Shenoy A, Kundapur SS, et al. Evaluation of the effect of different contaminants on the shear bond strength of a two-step self-etch adhesive system, one-step, self-etch adhesive system and a total-etch adhesive system. J Int Oral Health 2016;8(3):1. DOI: 10.2047/ jioh-08-03-15.

10. Hewlett ER. Resin adhesion to enamel and dentin: a review. J Calif Dent Assoc 2003;31(6):469-476. PMID:12859132.

11. Yaseen SM, Subba Reddy VV. Comparative evaluation of shear bond strength of two self-etching adhesives (sixth and seventh generation) on dentin of primary and permanent teeth: an in vitro study. J Indian Soc Pedod Prev Dent 2009;27(1):33-38. DOI: 10.4103/0970-4388.50814.

12. Loguercio $A D$, Martinez $L$, Munoz MA, et al. A comprehensive laboratory screening of three-step etch-and rinse adhesives. Oper Dent 2014;39(6):652-662. DOI: 10.2341/13-236.

13. Giannini M, Makishi P, Ayres AP, et al. Self-etch adhesive systems: a literature review. Braz Dent J 2015;26(1):3-10. DOI: 10.1590/01036440201302442.

14. Joseph P, Yadav C, Sathesh K, et al. Comparative evaluation of the bonding efficacy of sixth, seventh and eighth generation bonding agents: an in vitro study. Int Res J Pharm 2013;4:141-143. DOI:10.4103/0972-0707.124119.

15. Kamble SS, Kandasamy B, Thillaigovindan R, et al. In vitro comparative evaluation of tensile bond strength of $6 \mathrm{th}, 7 \mathrm{th}$ and 8 th generation dentin bonding agents. J Int Oral Health 2015;7(5):41-43. PMID:26028901, PMCID: PMC4441234.

16. Nikhil V, Singh V, Chaudhry S. Comparative evaluation of bond strength of three contemporary self-etch adhesives: an ex vivo study. Contemp Clin Dent 2011;2(2):94-97. DOI: 10.4103/0976-237X.83068.

17. Leite FRM, Capote TSO, Zuanon ACC. Application of the total etching technique or self-etching primers on primary teeth after air abrasion. Braz Oral Res 2005;19(3):198-202. DOI: 10.1590/s180683242005000300008

18. Mithiborwala S, Chaugule V, Munshi AK, et al. A comparison of the resin tag penetration of the total etch and the self-etch dentin bonding systems in the primary teeth: an in vitro study. Contemp Clin Dent 2012;3(2):158-163. DOI: 10.4103/0976-237X.96818.

19. De Munck J, Vargas M, Iracki J, et al. One day bonding effectiveness of new self-etch adhesives to bur cut enamel and dentin. Oper Dent 2005;30(1):39-49. PMID: 15765956.

20. Somani R, Jaidka S, Arora S. Comparative evaluation of microleakage of newer generation dentin bonding agents: an in vitro study. Indian J Dent Res 2016;27(1):86-90. DOI: 10.4103/0970-9290.179837.

21. Afshar H, Nakhjavani YB, Taban SR, et al. Bond strength of 5th, 6th and 7th generation bonding agents to intracanal dentin of primary teeth. J Dent 2015;12(2):90-98. PMID: 26056518, PMCID: PMC4434132. 